\title{
Aronia melanocarpa berries: phenolics composition and antioxidant properties changes during fruit development and ripening
}

\author{
Małgorzata Gralec, Iwona Wawer, Katarzyna Zawada* \\ Department of Physical Chemistry, Faculty of Pharmacy with the Laboratory Medicine Division, Medical University of Warsaw, Banacha 1 Str., \\ PL02097 Warsaw, Poland
}

\section{A B S T R A C T}

\begin{abstract}
Aronia melanocarpa E. (black chokeberry, aronia) is cultivated in Poland, the USA, Korea and many other countries worldwide. It is known that its ripening and ripe berries are a very rich source of polyphenolic antioxidants, however, there is no data concerning unripe fruits. In this work, the changes in the content of anthocyanins, procyanidins, total polyphenols, flavonoids and antioxidant activity (measured with ORAC and DPPH-EPR tests) of Aronia melanocarpa E., Nero cultivar, during the whole fruit development and ripening period were studied. The highest content of total polyphenols (up to $20 \mathrm{~g} / 100 \mathrm{~g} \mathrm{~d} . \mathrm{w}$. ), procyanidins (10-15 g/100 g d.w.) and flavonoids (7-11 g/100 g d.w.) as well as the highest antioxidant activity (up to $100 \mathrm{mmol}$ Trolox/100 g d.w.) was observed for unripe fruits. Procyanidins content declined during fruit development and then increased slightly in later maturation stages. Anthocyanin biosynthesis initiated at the beginning of fruit ripening and reached the highest level $(2-3 \mathrm{~g} / 100 \mathrm{~g} \mathrm{~d} . \mathrm{w}$.$) in mature fruit. Thus, although as for now only ripe berries are processed to$ obtain juice and extracts for foods, our results suggest that green berries rich in procyanidins and other phenolics may be an interesting raw plant material for both food and pharmaceutical industries.
\end{abstract}

Keywords: Aronia melanocarpa; Chokeberry; Antioxidants; Polyphenols; Anthocyanins; Green fruit

\section{INTRODUCTION}

Though Aronia melanocarpa E. (black chokeberry, aronia) is native to eastern North America, it is cultivated extensively in Europe and in Asia. The aronia fruit is a very rich source of dietary antioxidants (Oszmiański and Wojdyło, 2005; Kulling and Rawel, 2008). Ripe A. melanocarpa berries contain various types of compounds: anthocyanins, procyanidins and flavonols (quercetin glycosides) (Wu et al., 2004; Slimestad et al., 2005). These polyphenolic components of fruits make them a valuable material which can be used as food or food supplements dedicated to protect from oxidative stress (Battino et al., 2009). On the other hand, it has been suggested that also unripe fruits can be a valuable material with better antioxidant properties than mature fruits (Wang and Lin, 2000; Castrejón et al., 2008, Tulipani et al., 2011). However, although the properties and chemical composition of ripe aronia fruits are well known, green aronia fruits have not been studied so far. Green aronia fruits are sour and bitter and are not suitable for direct human consumption. Still, procyanidins, flavonoids and other secondary metabolites can be beneficial for human health when extracted from fruits.

The consumption of $A$. melanocarpa berries could have a positive impact on human health (Banjari et al., 2017; Chrubasik et al., 2010; Gawryś et al., 2012; Jurikova et al., 2017; Kokotkiewicz et al., 2010; Kulling, 2008). Numerous studies indicated that aronia extracts from ripe fruits have anticancerous (Gasiorowski et al., 1997; Malik et al., 2003), antidiabetic (Simeonov et al., 2002, Baum et al., 2016) and anti-inflammatory (Ryszawa et al., 2006) properties, reduce blood pressure (Bell and Gochenaur, 2006) and alleviate the toxicity of heavy metals (Kowalczyk et al., 2003).

Phenolic compounds and the antiradical activity of different cultivars of aronia were compared during two consecutive years (Jakobek et al., 2012). Although the profile of

\footnotetext{
*Corresponding author:

Katarzyna Zawada, Department of Physical Chemistry, Faculty of Pharmacy with the Laboratory Medicine Division, Medical University of Warsaw, Banacha 1 Str., PL02097 Warsaw, Poland. Tel.: +(48) 225720950, E-mail: katarzyna.zawada@wum.edu.pl
}

Received: 21 January 2019; $\quad$ Accepted: 30 March 2019 
polyphenols was the same, some differences were found in the content of these compounds. Such differences were also observed by Howard et al. (2003) for various cultivars of blueberries and by Lestario et al. (2017) for Java plum. The present research work describes the major chemical changes and antioxidant activity of Polish cultivar "Nero" during three seasons of fruit development. The aim of the study was the determination of the optimal collection time in order to get aronia berries rich in particular groups of polyphenolic compounds.

Although there are available numerous studies on the changes in bioactive compounds during aronia maturation process (Jeppsson and Johansson, 2000; Banjari et al., 2015; Bolling et al., 2015), there is no information concerning the first stages of development, i.e., unripe fruits. Thus, the composition of phenolic compounds in fruits in different development stage (i.e., unripe, ripening and ripe) was examined. Since the biological activity of $A$. melanocarpa components is usually attributed to their antioxidant properties, these characteristics of aronia berries in different stages of development were studied as well.

Many assays are used for estimating antioxidant activity of a vegetable or fruit matrix. DPPH and ORAC are the two most common tests, and have been used to measure the antioxidant activity of e.g. sweet orange juice (Giuffrè et al., 2017a), coffee (Yashin et al., 2013), guava fruit extracts (Thaipong et al., 2006) as well as edible vegetable oils (Giuffrè et al., 2016; Giuffrè et al., 2017b). Therefore, DPPH and ORAC tests were chosen, as they are the assays most often applied to aronia fruit as well, to enable comparison with earlier studies on the antioxidant properties of berries.

\section{MATERIALS AND METHODS}

\section{Plant material}

Fruits of Aronia melanocarpa E. ("Nero" cultivar) were collected from May to August in 2012, 2013 and 2016 at the plantation in Mazowieckie District, Poland. The plants were six years old. The local climate is warm-summer humid continental climate, "Dfb" according to the Köppen classification. The average annual temperature and precipitation of the region are of $7.5^{\circ} \mathrm{C}$ and $550-600 \mathrm{~mm}$, respectively. The plants were rain-fed only (no irrigation). The fertilization pattern was the same in all studied years, mineral fertilization only, applied in May.29 May was arbitrarily taken as the first day of fruit development (day 0). Collected fruits were frozen and stored at $-15^{\circ} \mathrm{C}$. They were classified according to their color as unripe (green fruit), ripening (pink tinted green to red fruit) and ripe (purple-black fruit).

\section{Sample preparation}

The extraction procedure was based on that proposed by Oszmiański and Wojdyło (2005). Frozen chokeberries were lyophilized and ground. Three independent batches from every sample (described by date of collection, $1 \mathrm{~g}$ each) were extracted with methanol acidified with $1 \mathrm{~g} / \mathrm{kg}$ $\mathrm{HCl}$. The extraction was performed by sonication for 20 minutes at room temperature. After that, the samples were centrifuged and supernatants were used for further analysis of antioxidant activity, as well as the content of anthocyanins, procyanidins and flavonoids. Some studies were performed immediately after the collection of supernatants, and for other analyses the samples were stored at $-30^{\circ} \mathrm{C}$ for a maximum of two weeks.

\section{Analytical procedures \\ Total anthocyanins content}

The content of anthocyanin was determined using the pH-differential method (Giusti and Wrolstad, 2001) using Evolution 60S spectrophotometer (Thermo-Fisher, USA). The content of anthocyanin pigment was calculated for each extract and expressed as cyanidin-3-glucoside equivalent (C3GE) in $\mathrm{g} / 100 \mathrm{~g}$ d.w. of fruits.

\section{Total flavonoids content}

The method proposed by Christ and Müller (1960) was used to determine the content of flavonoids. The absorbance at $510 \mathrm{~nm}$ was measured using Evolution $60 \mathrm{~S}$ spectrophotometer (Thermo-Fisher, USA). The results were expressed as catechin equivalent (CE (g/100 g d.w.)).

\section{Total procyanidins content}

Procyanidin content was determined with vanillin method and the parameters were based on the study of Sun et al. (1998). The absorbance was measured at $500 \mathrm{~nm}$ by Evolution $60 \mathrm{~S}$ spectrophotometer (Thermo-Fisher, USA). Results were expressed as epicatechin equivalents (EE (g/100g d.w.)).

\section{Total phenolics content (TP)}

Folin-Ciocalteu colorimetric method (Singleton et al., 1999) was used to determine total phenolics. Briefly, $20 \mu \mathrm{l}$ of a diluted extract samples were placed in each microplate's well and then $100 \mu \mathrm{l}$ of Folin-Ciocalteu reagent $(0.3 \mathrm{~mol} / \mathrm{L})$ was added to each well. The mixture was kept in the dark for 5 minutes at room temperature. Then $50 \mu \mathrm{l}$ of $200 \mathrm{~g} / \mathrm{L}$ sodium carbonate was added. The mixture was incubated for 20 minutes at $37^{\circ} \mathrm{C}$. The absorbance at $765 \mathrm{~nm}$ was measured using microplate reader Synergy Mx (Biotec, USA). The results were expressed as gallic acid equivalents (GAE (mg/100g d.w.)).

\section{$D P P H-E P R$ radical scavenging assay}

The 2,2-diphenyl-1-picrylhydrazyl (DPPH) radical scavenging test was used to determine the antioxidant 
activity (Sanna et al., 2012). The extracts are coloured and/or cloudy, thus for popular spectrophotometric UV-vis measurements the background corrections for absorbance are necessary. Therefore, radical scavenging activity was estimated by electron paramagnetic resonance (EPR) spectroscopy. EPR spectra were measured at ambient temperature (298 K) on a MiniScope MS200 EPR spectrometer (Magnettech, Germany). The samples were diluted with methanol (30-100 fold). Equal volumes of a diluted extract and of DPPH methanolic solution (3.4 mmol/L) were mixed, and after 20 minutes EPR spectra were taken. The intensity of registered EPR spectra was compared with the control sample (methanol in place of an extract). The results were expressed as Trolox equivalents (TE) in mmol TE and recalculated for $100 \mathrm{~g} \mathrm{~d}$.w.

\section{ORAC-fluorescein (ORAC-FL) assay}

The method is based on that proposed by Ou et al. (2001). All solutions were prepared in PBS (phosphate-buffered saline), pH 7.4. For measurements, $30 \mu$ l of the chokeberry extract diluted with PBS (100-500 fold), standard (Trolox) solution or, in case of a blank, $30 \mu$ l of PBS buffer, were mixed with $180 \mu \mathrm{l}$ of $112 \mathrm{nmol} / \mathrm{L}$ fluorescein solution in a well of 96-well plate and thermostated for 15 minutes at $37^{\circ} \mathrm{C}$. Then, $100 \mu \mathrm{l}$ of $100 \mathrm{mmol} / \mathrm{L} \mathrm{AAPH}$ solution was added. Fluorescence was measured with F-7000 Fluorescence Spectrophotometer (Hitachi, Japan) equipped with a Micro Plate Reader every 70 s for 90 minutes. The reaction mixture was thermostated at $37^{\circ} \mathrm{C}$. ORAC values expressed as Trolox equivalents (TE (mmol/100g d.w.)) were calculated using the standard curve.

\section{HPLC/MS characterization of fruit contents}

Characterization of contents of methanolic extracts from unripe, ripening and ripe aronia fruit was performed using
Ultra-Performance Liquid Chromatograph ACQUITY UPLC I-Class (Waters Inc) coupled with Synapt G2-S HDMS (Waters Inc) mass spectrometer equipped with an electrospray ion source and q-TOF type mass analyzer. The ACQUITY UPLCR BEH C18 1.7um (WATERS) column was used. The mobile phase consisted of $0.1 \%$ formic acid in water (solvent A) and methanol (solvent B) with the following gradient conditions: $95 \% \mathrm{~A}$ at $0-2 \mathrm{~min}$, 95-0\% $\mathrm{A}$ at 2-15 $\mathrm{min}, 0 \% \mathrm{~A}$ at $15-22 \mathrm{~min}, 0-95 \% \mathrm{~A}$ at 22-22.10 $\mathrm{min}$ and $95 \% \mathrm{~A}$ at $22.10-25 \mathrm{~min}$. The flow rate was $0.3 \mathrm{~mL} / \mathrm{min}$.

\section{Statistical analyses}

Statistical analysis (one-way ANOVA, correlation analysis) was performed with Statistica 10 (StatSoft Inc.) software. The Scheffe test was applied to assess significant differences $(\mathrm{p}<0.05)$ between samples.

\section{RESULTS AND DISCUSSION}

\section{The content of bioactive compounds}

The content of the main groups of compounds: anthocyanins, flavonoids and procyanidins, as well as the content of total phenolics, change in time during fruit development and ripening. The results are shown in Fig. 1.

At the beginning of fruit development, the berries are green and do not contain anthocyanins. These compounds appear later as the fruits are ripening. An increase in the anthocyanin pigment concentration was observed in aronia fruits between $30^{\text {th }}$ and $80^{\text {th }}$ day of fruit development (Fig. 1a). The content of anthocyanins increases from about $1 \mathrm{~g} / 100 \mathrm{~g}$ of dry weight in the last days of July $\left(50^{\text {th }}-55^{\text {th }}\right.$ day of fruits development $)$ to $2-3 \mathrm{~g} / 100 \mathrm{~g}$

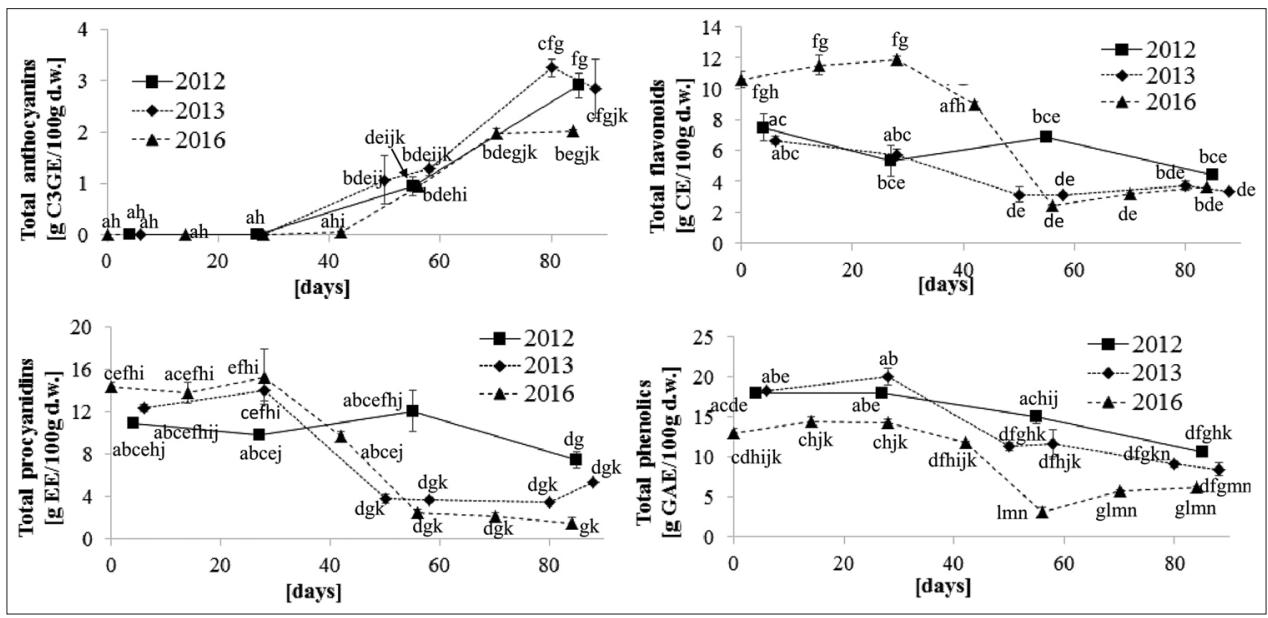

Fig 1. Content of (a) anthocyanins, expressed as cyanidin-3-glucoside equivalent (C3GE) in g/100 g d.w., (b) flavonoids in aronia berries, expressed as catechin equivalent (CE [g/100 g d.w.]), (c) procyanidins in aronia berries, expressed as epicatechin equivalents (EE [g/100g d.w.]), (d) total phenolics in aronia berries, expressed as gallic acid equivalents (GAE [mg/100g d.w.] in aronia berries as the function of time during three vegetation seasons. Error bars correspond to standard deviation of three repetitions. Samples with the same letters are not significantly different (one-way ANOVA, Sheffe test, $\mathrm{p}>0.05$ ). 
in August $\left(80^{\text {th }}-90^{\text {th }}\right.$ day). The highest concentration of anthocyanins was recorded in ca. 80 day-old fruit. A slight, 10\%, decrease in 2013 observed at the end of collection period may be due to a decrease in acidity. It was observed (Holcroft and Kader, 1999) that the stability of anthocyanins as well as their biosynthesis could decrease with the decrease in acidity. This tendency of changes in anthocyanin content is similar to that observed by other authors (Jeppsson and Johansson, 2000; Andrzejewska et al., 2015; Bolling et al., 2015). It should be noted, though, that in previous studies the fruits were collected only during the ripening period and later (August - October).

The tendency of changes in anthocyanin content is similar in all three vegetation seasons, but fruits collected in 2016 have lower final content of anthocyanins than those harvested in previous years. The differences in concentrations and the progress of ripening could be tentatively connected with weather, as the vegetation season of 2016 was characterized by lower, than in previous years, temperature in August (the average temperature in this month in 2012 was $18.9^{\circ} \mathrm{C}$, in $201319.3^{\circ} \mathrm{C}$ and in $201616.9^{\circ} \mathrm{C}$ (https:// www.wunderground.com/history/). Weather conditions, such as temperature and insolation, influenced phenolics content in juice of aronia, as shown recently (Tolic et al., 2017). As there was no change in irrigation or fertilization pattern among years, these differences cannot be caused by the variation of cultivation conditions.

The analysis of anthocyanins content confirmed that ripe Aronia melanocarpa fruit is a rich source of these phenolics (2-3 g/100 $\mathrm{g} \mathrm{d.w.).} \mathrm{It} \mathrm{is} \mathrm{consistent} \mathrm{with} \mathrm{the} \mathrm{findings} \mathrm{of}$ Oszmiański and Wojdyło (2005) (2 g/100 g d.w. of ripe aronia fruit) as well as of Kapci et al. (2013) (about $2 \mathrm{~g} / 100 \mathrm{~g}$ d.w., assuming the average water content of ca. $800 \mathrm{~g} / \mathrm{kg}$ of fresh fruit). Aronia fruit contains more anthocyanins than blueberry (about two times more), açaí (about four times more) and goji (even 350 times more) (de Moura et al., 2018).

The highest level of flavonoids, determined by Christ and Müller method, was observed in unripe fruits. It amounts from $7 \mathrm{~g} / 100 \mathrm{~g} \mathrm{~d}$.w. in 2012 and $2013 \mathrm{up}$ to $11 \mathrm{~g} / 100 \mathrm{~g} \mathrm{~d}$.w. in 2016. The content of these compounds is declining to about $4 \mathrm{~g} / 100 \mathrm{~g}$ d.w. as fruits are ripening, as illustrated in Fig. 1b. It stays at the same level in August, until the end of observation. More rapid decrease of flavonoid content is observed in case of fruits collected in 2016 than for these collected in 2012 and 2013. The results of our analysis are similar to the findings of Oszmiański and Wojdyło (2005) (2.1 g/100 g d.w. of all analysed by HPLC flavonoids, i.e., sum of anthocyanins and quercetin glycosides). Kapci et al. (2013), using the Christ-Müller method, obtained values of 1.99 and $1.25 \mathrm{~g} / 100 \mathrm{~g}$ for dried chokeberry fruits.

It is worth mentioning that in the conventional oven-drying of fruit there is usually a larger decrease in flavonoid content than during freeze-drying (Thi and Hwang, 2016) which was used in our work. It could be the reason of lower values of Kapci et al. (2013). As Bolling et al. (2015) analyzed the bioactive compounds in juice obtained from aronia fruits harvested at different time points during the ripeness period (August - September), it is difficult to compare values of flavonoid content. Still, in their work no apparent trend of changes by harvest date was observed, similarly to our work.

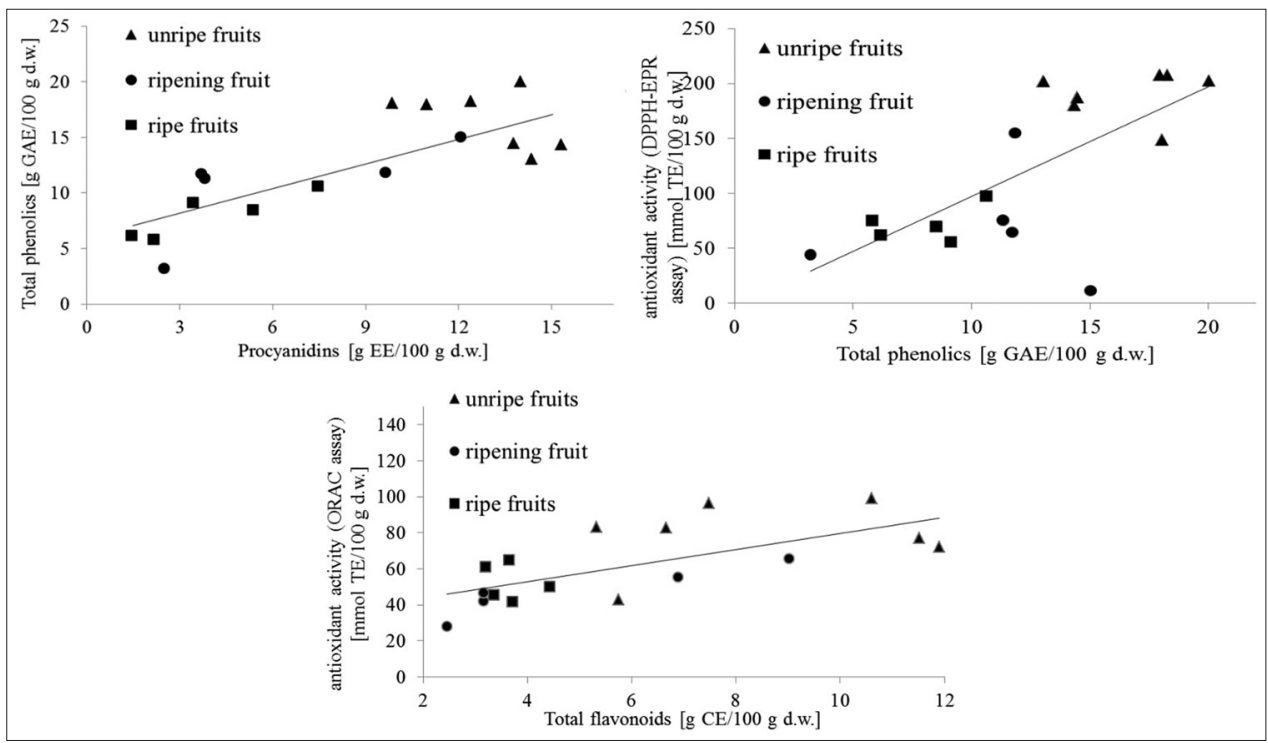

Fig 2. Correlation between: (a) total phenolics content and procyanidin content (the correlation parameters: $r=0.81, p<0.05$ ), (b) the results of DPPH test and total phenolics content (the correlation parameters: $r=0.70, p<0.05$ ), (c) the results of ORAC test and total flavonoids content (the correlation parameters: $r=0.77, p<0.05$ ) of aronia berries in different stages of development. 
Similar situation to the one with flavonoids is observed in the case of procyanidins. Their concentration decreases during maturation of fruits. The amount of these compounds is within $10 \mathrm{~g}$ to $15 \mathrm{~g} / 100 \mathrm{~g}$ d.w. in May and June (0-28 day), for green fruits, and declines in August (70-88 day) to about $8 \mathrm{~g} / 100 \mathrm{~g}$ d.w. in 2012, $4-5 \mathrm{~g} / 100 \mathrm{~g}$ d.w. in 2013, and even to $1 \mathrm{~g}$ d.w. in 2016. It stays at this level in ripe fruits (Fig. 1c). It is in agreement with the findings of Wu et al. (2004) (about $2.5 \mathrm{~g}$ in ripe aronia, assuming $800 \mathrm{~g} / \mathrm{kg}$ water content of fresh fruit). The larger decrease of procyanidin content is observed in fruits collected in 2013 and 2016 than in 2012. The content of procyanidins observed by us during the whole ripeness period is contrary to that noticed by Bolling et al. (2015), where this content, determined with DMAC method, increased with time.

Aronia showed the highest total phenolics concentration during the initial stage of fruit development; ca. $20 \mathrm{~g} / 100 \mathrm{~g}$ d.w. was recorded in 30 day-old fruit (Fig. 1d). It is a much higher value than the one obtained for unripe blueberries (4- 7 g/100 g d.w.) (Castrejón et al., 2008) or thornless blackberry (2 g/100 g d.w.) (Wang and Lin, 2000). Later, there was a significant reduction in total phenolics from $30^{\text {th }}$ to $90^{\text {th }}$ day of fruit development. A decrease in phenolic compounds content with maturation and ripening has also been reported in guava (Bashir and Abu-Goukh, 2003), blueberry (Castrejón et al., 2008) and other fruits.

The positive correlation between total content of phenolic compounds and procyanidins has been observed (illustrated in Figure 2a). No significant correlation was observed between other groups of active compounds present in the berries. Thus, procyanidins are mainly responsible for the changes in total phenolics content of $A$. melanocarpa fruits during ripening. A weak correlation between total phenolic compounds and procyanidins content was also observed by Bolling et al. (2015) for ripe aronia berries collected from August to September, which is in agreement with our findings.

Although there was no correlation between total anthocyanin and total polyphenol content when the whole season has been taken into account, a decrease in total phenolics (Fig. 1d) coincided with an increase in anthocyanin pigment content (Fig. 1a). A similar effect was observed for blueberries by Castrejón et al. (2008) during fruit development and ripening. A decrease in the content of total phenolics and especially procyanidins reduces the astringency of fruit which is a desirable sensory attribute. The increase of anthocyanins concentration enhances the color and visual attractiveness of the fruit.

\section{Antioxidant activity}

Oxidative stress is suspected to be an important factor in developing neurodegenerative (Patel and Chu, 2011) and cardiovascular diseases (Csányi and Miller, 2014). Consuming food rich in antioxidants could protect our bodies from oxidative stress (Bjørklund and Chirumbolo, 2017). The radical-scavenging-linked antioxidant properties of the extracts from black chokeberry cultivated in Korea was investigated (Hwang et al., 2014). The results suggest that black chokeberry extracts could be considered as a good source of natural antioxidants and functional food ingredients.

As the biological activity of $A$. melanocarpa berries is often ascribed to their antioxidant properties, it seemed worth checking the relation between the content of active substances and antioxidant activity of fruits. The antioxidant activity of aronia fruits collected at various stages of development was determined with the DPPHEPR and the ORAC tests.

DPPH radical scavenging assay is the most popular screening test for antioxidants. It is usually performed with spectrophotometric monitoring of DPPH concentration. It should be noted, though, that many food components can interfere with such measurements as their absorption spectra overlap with the DPPH radical UV-vis spectrum. Furthermore, in polar solvents the aggregation of DPPH could take place and influence the results. Both problems

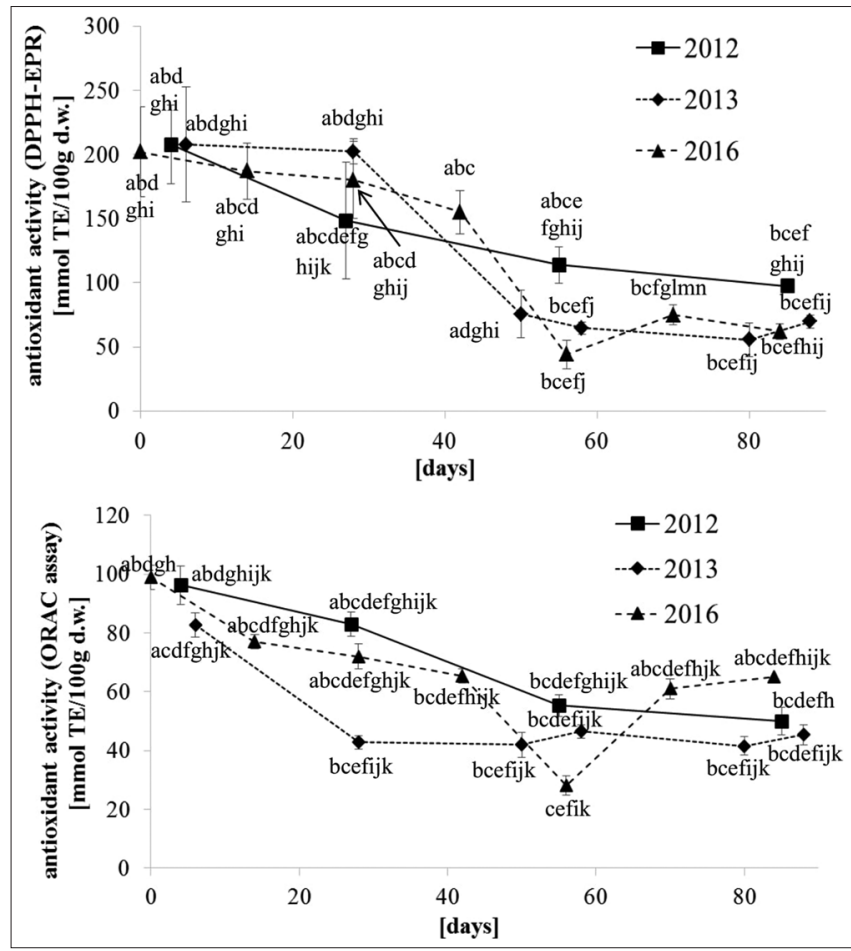

Fig 3. Antioxidant activity determined with (a) DPPH-EPR assay, (b) ORAC assay, expressed as Trolox equivalents (TE [mmol/100g d.w.]), as the function of time during three vegetation seasons. Error bars correspond to standard deviation of three repetitions. Samples with the same letters are not significantly different (one-way ANOVA, Sheffe test, $p>0.05$ ). 
Table 1. HPLC-MS identification of phenolic compounds in A. melanocarpa fruit in different stages of development

\begin{tabular}{|c|c|c|c|c|c|}
\hline \multirow[t]{2}{*}{ Compound } & \multirow{2}{*}{$\begin{array}{l}\text { Retention time } \\
\text { [min] }\end{array}$} & \multirow[t]{2}{*}{$\mathrm{m} / \mathrm{z}(\mathrm{ES}+)$} & \multicolumn{3}{|c|}{ AUC } \\
\hline & & & $\begin{array}{l}\text { Unripe } \\
\text { (green) } \\
\text { fruit }\end{array}$ & $\begin{array}{l}\text { Ripening } \\
\text { (pink } \\
\text { tinted } \\
\text { green to } \\
\text { red) fruit }\end{array}$ & $\begin{array}{l}\text { Ripe } \\
\text { (purple) } \\
\text { fruit }\end{array}$ \\
\hline $\begin{array}{l}\text { Cyanidin 3-O- } \\
\text { galactoside }\end{array}$ & 6.73 & 449.11 & nd & 1247 & 397334 \\
\hline $\begin{array}{l}\text { Cyanidin 3- } \\
\text { arabinoside }\end{array}$ & 7.07 & 419.10 & nd & nd & 185650 \\
\hline \multirow[t]{2}{*}{ Compound } & \multirow{2}{*}{$\begin{array}{l}\text { Retention time } \\
\text { [min] }\end{array}$} & \multirow[t]{2}{*}{$\mathrm{m} / \mathrm{z}(\mathrm{ES}-)$} & \multicolumn{3}{|c|}{ AUC } \\
\hline & & & $\begin{array}{l}\text { Unripe } \\
\text { (green) } \\
\text { fruit }\end{array}$ & $\begin{array}{l}\text { Ripening } \\
\text { (pink } \\
\text { tinted } \\
\text { green to } \\
\text { red) fruit }\end{array}$ & $\begin{array}{l}\text { Ripe } \\
\text { (purple) } \\
\text { fruit }\end{array}$ \\
\hline $\begin{array}{l}\text { Chlorogenic } \\
\text { acid/neochlorogenic } \\
\text { acid }\end{array}$ & $5.42,6.49$ & 353.09 & 16940 & 12569 & 18673 \\
\hline Catechin, epicatechin & 6.76 & 289.07 & 4056 & nd & nd \\
\hline Quercetin 3-rutinoside & 9.00 & 609.15 & 3364 & 2882 & 6793 \\
\hline $\begin{array}{l}\text { Quercetin 3- } \\
\text { glucoside/ Quercetin } \\
\text { 3-galactoside }\end{array}$ & $8.15,9.02$ & 463.10 & $\begin{array}{l}1895 \\
5859\end{array}$ & $\begin{array}{l}1543, \\
6524\end{array}$ & $\begin{array}{l}1810, \\
13572\end{array}$ \\
\hline Kaempferol & 8.86 & 285.1 & nd & nd & 3020 \\
\hline
\end{tabular}

can be avoided with the use of EPR spectroscopy, as it is sensitive only to substances with unpaired electrons and also immediately shows the DPPH aggregation (Sanna et al., 2012).

ORAC assay is based on the ability of antioxidants present in the sample to inhibit the oxidation of a probe by peroxyl radicals. Recently, a move to widen the spectrum of reactive oxygen and nitrogen species used in this test in order to better predict the in vivo activity of a given antioxidants source has been proposed (Prior et al., 2016).

The results of antioxidant activity determination are presented in Fig. 3. Results of these tests indicate that unripe fruits of $A$. melanocarpa collected at the beginning of growth have higher antioxidant activity than the ripe ones. There is a statistically significant difference in antioxidant activity of unripe and ripe aronia fruits. A similar tendency in ORAC values was observed for other berries, e.g. black raspberry or thornless blackberry (Wang and Lin, 2000), however, the obtained values (16 and $18 \mathrm{mmol}$ Trolox/100 g d.w., respectively) were much lower than for aronia (up to $100 \mathrm{mmol}$ Trolox/100 g d.w.).

The antioxidant activity was similar, considering their values as well as the tendency to decrease during fruit growth and maturation, for fruits harvested in all three vegetation seasons. The fruits collected at the end of May (day 0) and at the beginning of June (days 3-6) exhibited the highest antioxidant activity. Then it decreased significantly during July (days 32-63), when maturation took place, to reach plateau in August (days 64-95).

Antioxidant properties of aronia determined with the DPPH test positively correlate with the content of total polyphenols both for ripe and unripe fruit, as illustrated in Fig. 2b, while the results of ORAC test positively correlate with the content of total flavonoids, as illustrated in Fig. 2c. It may be explained by different mechanisms of these antioxidant assays. There is no significant correlation between antioxidant properties determined by any of the assays and the content of anthocyanins. Thus, it suggests that the antioxidant activity of $A$. melanocarpa berry extracts is due to different groups of bioactive compounds than anthocyanins.

\section{HPLC/MS analysis}

According to the HPLC chromatograms and the mass spectrometry results, the main anthocyanin in aronia fruit was cyanidin-3-galactoside, which was detected in ripening and ripe fruit (Table 1). The presence of second anthocyanin, cyanidin 3-arabinoside was observed only in ripe fruit, whereas the catechin was detected only for unripe (green) fruit. The highest concentration of chlorogenic acids and quercetin derivatives was determined for ripe fruit, followed by unripe fruit. For ripening fruit the temporary decrease in their concentration was observed.

\section{CONCLUSIONS}

The Aronia melanocarpa fruits are a rich source of phenolics. Chemical composition of the berries significantly changes during fruit development and ripening. Collection of the berries as a food and food supplements material should take into account the changes in chemical components during ripening. The green, unripe fruits have the highest antioxidant activity due to the high content of procyanidins and flavonoids, in spite of the absence of anthocyanins. Thus, the extracts of green fruits could be potentially used as a dietary supplement in prophylactics as well as dietary support of the therapies. The polyphenol-rich extracts may be especially useful for patients with metabolic syndrome where the severe oxidative stress occurs. In our opinion, the extract of green berries, rich in polyphenols and exhibiting strong antioxidant activity, could be an interesting new material for dietary supplements and deserves further studies. On the other hand, fruits harvested in August are characterized by the highest content of anthocyanins, and could be used as an important dietary component for people with diabetes and as the support of therapy of cardiovascular diseases. In summary, the current study revealed that fruit development and ripening process affects polyphenolic compounds composition and content. Understanding the pattern of their concentration changes can contribute to improving breeding and harvest strategies.

\section{ACKNOWLEDGMENT}

This work was supported by the Polish National Science Center [grant number 2015/17/B/NZ7/03089]. 


\section{Authors' contributions}

M.G. collected plant material, M.G. and K.Z. performed the measurements, I.W. and K.Z. were involved in planning and supervised the work, M.G. and K.Z. processed the experimental data, performed the analysis, drafted the manuscript and designed the figures. All authors discussed the results and commented on the manuscript.

\section{REFERENCES}

Andrzejewska, J., K. Sadowska, Ł. Klóska and L. Rogowski. 2015. The effect of plant age and harvest time on the content of chosen components and antioxidative potential of black chokeberry fruit. Acta Sci. Pol. Hortic. 14: 105-114.

Banjari I., A. Misir, K. Šavikin, S. Jokić, M. Molnar, H. De Zoysa, and V.Y. Waisundara. 2017. Antidiabetic effects of Aronia melanocarpa and its other therapeutic properties. Front. Nutr. 53: 1-6.

Bashir, H. A. and A. Abu-Goukh. 2003. Compositional changes during guava fruit ripening. Food Chem. 80: 557-563.

Battino, M., J. Beekwilder, B. Denoyes-Rothan, M. Laimer, G. J. McDougall and B. Mezzetti. 2009. Bioactive compounds in berries relevant to human health. Nutr. Rev. 67: S145-S150.

Baum, J. I., L.R. Howard, R. L. Prior and S. O. Lee. 2016. Effect of Aronia melanocarpa (Black Chokeberry) supplementation on the development of obesity in mice fed a high-fat diet. J. Berry Res. 6: 203-212.

Bell, D. R. and K. Gochenaur. 2006. Direct vasoactive and vasoprotective properties of anthocyanin-rich extracts. J. Appl. Physiol. 100: 1164-1170.

Bjørklund, G. and S. Chirumbolo. 2017. Role of oxidative stress and antioxidants in daily nutrition and human health. Nutrition. 33: 311-321.

Bolling, B. W., R. Taheri, R. Pei, S. Kranz, M. Yu, S.N. Durocher and M.H. Brand. 2015. Harvest date affects Aronia juice polyphenols, sugars, and antioxidant activity, but not anthocyanin stability. Food Chem. 187: 189-196.

Castrejón, A. D. R., I. Eichholz, S. Rohn, L. W. Kroh and S. Huyskens-Keil. 2008. Phenolic profile and antioxidant activity of highbush blueberry (Vaccinium corymbosum L.) during fruit maturation and ripening. Food Chem. 109: 564-572.

Christ, B. and K. H. Müller. 1960. Zur serienmaessigen bestimmung des gehaltes an flavonol-derivaten in drogen. Arch. Pharm. 293: 1033-1042.

Chrubasik, C., G. Li and S. Chrubasik. 2010. The clinical effectiveness of chokeberry: A systematic review. Phytother. Res. 24: 1107-1114.

Csányi, G. and F. J. Miller. 2014. Oxidative stress in cardiovascular disease. Int. J. Mol. Sci. 15: 6002-6008.

de Moura, C., A. Soares dos Reis, L. D. da Silva, V. A. de Lima, T. L. C. Oldoni, C. Pereira and S. T. Carpes. 2018. Optimization of phenolic compounds extraction with antioxidant activity from açaí, blueberry and goji berry using response surface methodology. Emir. J. Food Agric. 30: 180-189.

Gasiorowski, K., K. Szyba, B. Brokos, B. Kolaczynska, M. J. Wlodarczyk and J. Oszmianski. 1997. Antimutagenic activity of anthocyanins isolated from Aronia melanocarpa fruits. Cancer Lett. 119: 37-46.

Gawryś, M., K. Zawada, and I. Wawer. 2012. Aronia w diabetologii. Diabet. Clin. 1: 196-200.
Giusti, M. M. and R. E. Wrolstad. 2001. Characterization and measurement of anthocyanins by UV-visible spectroscopy. In: Wrolstad, R. E. and S. J. Schwartz, editors. Current Protocols in Food Analytical Chemistry. John Wiley and Sons, Inc. New York., USA, pp. F1.2.1-F1.2.13.

Giuffrè, A. M., S. Tellah, M. Capocasale, C. Zappia, M. Latati, M. Badiani and S. M. Ounane. 2016. Seed oil from ten Algerian peanut landraces for edible use and biodiesel production. J. Oleo Sci. 65: 9-20.

Giuffrè, A. M., C. Zappia and M. Capocasale. 2017a. Physicochemical stability of blood orange juice during frozen storage. Internat. J. Food Properties 20: 1930-1943.

Giuffrè, A. M., C. Zappia and M. Capocasale. 2017b. Tomato seed oil for edible use: Cold break, hot break and harvest year effects. J Food Proc. Preserv. 41: e13309.

Holcroft, D. M. and A. A. Kader. 1999. Carbon dioxide induced changes in color and anthocyanin synthesis of stored strawberry fruit. Hortiscience. 34: 1244-1248.

Howard, L. R., J. R. Clarkand and C. Brownmiller. 2003. Antioxidant capacity and phenolic content in blueberries as affected by genotype and growing season. J. Sci. Food Agric. 83: 1238-1247.

Hwang, S. J., W. B. Yoon, O. H. Le, S. J. Cha and J. D. Kim. 2014 Radical-scavenging-linked antioxidant activities of extracts from black chokeberry and blueberry cultivated in Korea. Food Chem. 146: 71-77.

Jakobek, L., M. Drenjancević, V. Jukić and M. Šeruga. 2012. Phenolic acids, flavonols, anthocyanins and antiradical activity of "Nero","Viking","Galicianka" and wild chokeberries. Sci. Horticult. 147: 56-63. Available from: https://www.wunderground.com/ history. [Last accessed on $2018 \mathrm{Jul} 27$ ].

Jeppsson, N. and R. Johansson. 2000. Changes in fruit quality in black chokeberry (Aronia melanocarpa) during maturation. J. Hortic. Sci. Biotechnol. 75: 340-345.

Jurikova, T., J. Mlcek, S. Skrovankova, D. Sumczynski, J. Sochor, I. Hlavacova, L. Snopek and J. Orsavova. 2017. Fruits of black chokeberry Aronia melanocarpa in the prevention of chronic diseases. Molecules. 944: 1-23.

Kapci, B., E. Neradová, H. Čížková, M. Voldřich, A. Rajchl and E. 2013. Capanoglu. Investigating the antioxidant potential of chokeberry (Aronia melanocarpa) products. J. Food Nutr. Res. 4: 219-229.

Kokotkiewicz, A., Z. Jaremicz and M. Luczkiewicz. 2010. Aronia plants: A review of traditional use, biological activities, and perspectives for modern medicine. J. Med. Food. 13: 255-269.

Kowalczyk, E., A. Kopff, P. Fijałkowski, M. Kopff, J. Niedworok, J. Błaszczyk, J. Kedziora, J and P. Tyślerowicz. 2003. Effect of anthocyanins on selected biochemical parameters in rats exposed to cadmium. Acta Biochim. Pol. 50: 543-548.

Kulling, S. E. and H. M. Rawel. 2008. Chokeberry (Aronia melanocarpa) a review on the characteristic components and potential health effects. Planta Med. 74: 1625-1634.

Lestario, L. N., L. R. Howard, C. Brownmiller, N. B. Stebbins, R. Liyanage and J. O. Lay. 2017. Changes in polyphenolics during maturation of Java plum (Syzygium cumini Lam.). Food Res. Int. 100: 385-391.

Malik, M., C. W. Zhao, N. Schoene, M. M. Guisti, M. P. Moyer and B. A. Magnuson. 2003. Anthocyanin-rich extract from Aronia melanocarpa $\mathrm{E}$. induces a cell cycle block in colon cancer but not normal colonic cells. Nutr. Cancer. 46: 186-196.

Oszmiański, J. and A. Wojdyło. 2005. Aronia melanocarpa phenolics and their antioxidant activity. Eur. Food. Res. Technol. 221: 809-813.

Ou, B., M. Hampsch-Woodill and R. L. Prior. 2001. Development and 
validation of an improved oxygen radical absorbance capacity assay using fluorescein as the fluorescent probe. J. Agric. Food Chem. 49: 4619-4626.

Patel, V. P. and C. T. Chu. 2011. Nuclear transport, oxidative stress, and neurodegeneration. Int. J. Clin. Exp. Pathol. 4: 215-229.

Prior, R. L., M. Sintara and T. Chang. 2016. Multi-radical (ORACMR5) antioxidant capacity of selected berries and effects of food processing. J. Berry Res. 6: 159-173.

Ryszawa, N., A. Kawczynska-Drozdz, J. Pryjma, M. CzesnikiewiczGuzik, T. Adamek-Guzik, M. Naruszewicz, R. Korbut and T. J. Guzik. 2006. Effects of novel plant antioxidants on platelet superoxide production and aggregation in atherosclerosis. J. Physiol. Pharmacol. 57: 611-626.

Sanna, D., G. Delogu, M. Mulas, M. Schirra, and A. Fadda. 2012. Determination of free radical scavenging activity of plant extracts through DPPH assay: An EPR and UV-Vis study. Food Anal. Method. 5: 759-766.

Simeonov, S. B., N. P. Botushanov, E. B. Karahanian, M. B. Pavlova, H. K. Husianitis and D. M. Troev. 2002. Effects of Aronia melanocarpa juice as part of the dietary regimen in patients with diabetes mellitus. Folia Med. 44: 20-23.

Singleton, V. L., R. Orthofer and R. M. Lamuela-Raventós. 1999. Analysis of total phenols and other oxidation substrates and antioxidants by means of folin-ciocialteu reagent. Methods Enzymol. 14: 155-158.

Slimestad, R., K. Torskangerpoll, H. S. Nateland, T. Johannessen and N. H. Giske. 2005. Flavonoids from black Chokeberries. J. Food Compos. Anal. 18: 61-68.
Sun, B., J. M. Ricardo-da-Silva and I. Spranger. 1998. Critical factors of vanillin assay for catechins and proanthocyanidins. J. Agric. Food Chem. 46: 4267-4274.

Thaipong, K., U. Boonprakob, K. Crosby, L. Cisneros-Zevallos and D. H. Byrne. 2006. Comparison of ABTS, DPPH, FRAP, and ORAC assays for estimating antioxidant activity from guava fruit extracts. J. Food Comp. Anal. 19: 669-675.

Thi, N. D. and E. S. Hwang. 2016. Effects of drying methods on contents of bioactive compounds and antioxidant activities of black chokeberries (Aronia melanocarpa). Food Sci. Biotechnol. 25: 55-61.

Tolić, M. T., I. P. Krbavcić, P. Vujević, B. Milinović, I. L. Jurcević and N. Vahcić. 2017. Effects of weather conditions on phenolic content and antioxidant capacity in juice of chokeberries (Aronia melanocarpa L.). Pol. J. Food Nutr. Sci. 67: 67-74.

Tulipani S., G. Marzban, A. Herndl, M. Laimer, B. Mezzetti and M. Battino. 2011. Influence of environmental and genetic factors on health-related compounds in strawberry. Food Chem. 124: 906-91.

Wang, Y. S. and H. S. Lin. 2000. Antioxidant activity in fruits and leaves of blackberry, raspberry, and strawberry varies with cultivar and developmental stage. J. Agric. Food Chem. 48: 140-146.

Wu, X., L. Gu, R. L. Prior and S. McKay. 2004. Characterization of anthocyanins and proanthocyanidins in some cultivars of Ribes, Aronia, and Sambucus and their antioxidant capacity. J. Agric. Food Chem. 52: 7846-7856.

Yashin, A., Y. Yashin, Y. Wang, B. Nemzer. 2013. Antioxidant and antiradical activity of coffee. Antioxidants. 2: 230-245. 